\title{
As Dimensões de Avaliação dos Atributos Importantes na Compra de Condicionadores de Ar: um Estudo Aplicado
}

\author{
Francine da Silveira Espinoza \\ Adriana Shizue Hirano
}

\begin{abstract}
Resumo
O principal objetivo deste trabalho é analisar a estrutura dos atributos considerados importantes pelos consumidores no momento da decisão de compra, à luz das tipologias apresentadas por Alpert (1971), Zeithaml (1988) e Peter e Olson (1999). Para tanto, foi realizada uma pesquisa exploratória, que se divide em uma etapa qualitativa, a qual buscou identificar os atributos considerados importantes por compradores de aparelhos de ar condicionado, e uma etapa quantitativa, que teve por objetivo analisar a estrutura subjacente à avaliação destes atributos. Com este propósito, foi aplicada a técnica estatística denominada Análise Fatorial Exploratória sobre os dados da amostra. Os resultados indicam que os atributos do produto considerados na compra são avaliados pelos consumidores em quatro dimensões, relacionadas aos tipos de atributos revisados no referencial teórico. Ao final, são discutidas as implicações gerenciais e acadêmicas dos resultados obtidos.
\end{abstract}

Palavras-chaves: comportamento do consumidor; processo de decisão de compra; atributos do produto; análise fatorial exploratória.

\section{Abstract}

This article aims at evaluating the structure of the product attributes considered important by customers at the moment of the purchase decision making, enlightened by three typologies (Alpert, 1971; Zeithaml, 1988; Peter e Olson, 1999). An exploratory study divided in a qualitative stage, which helped to identify the attributes considered important by recent buyers of air conditioner equipment, and a quantitative stage, in which the underlying attribute evaluation structure was analyzed, was conducted. For this purpose, Exploratory Factorial Analysis (EFA) technique was used to analyze the sample data. Results show that the product attributes are evaluated under four dimensions, which are related to the revised theories. Finally, managerial and academic implications of our findings are discussed.

Key words: consumer behavior; consumer decision process; product attributes; exploratory factor analysis. 


\section{INTRODUÇÃO}

Um aspecto muito importante em pesquisas relacionadas ao comportamento do consumidor é a identificação das verdadeiras razões que levam os consumidores a decidir a compra dos produtos. Conhecer os atributos mais importantes no julgamento do comprador é uma informação crítica para as decisões tomadas por profissionais de marketing. Os atributos têm pesos muito diferentes em relação a sua importância, o que torna pertinente conhecer o que realmente se passa na mente do consumidor (Mowen e Minor, 1998). Além disso, o estudo de atributos do produto torna-se relevante, na medida em que impacta na formação de atitude do consumidor, considerando-se que há uma corrente de pesquisa que afirma que a atitude é função da importância que o consumidor designa aos atributos do produto (Allen, Ng e Wilson, 2002).

Como aplicação prática de estudos dessa natureza, salienta-se a possibilidade de melhor posicionar o produto no mercado. Por exemplo, no caso de maior importância ser dispensada aos atributos intrínsecos, cabe ao marketing enfatizar as características do produto, buscando salientar as vantagens do seu produto em relação à concorrência. Por outro lado, se os atributos extrínsecos são os de maior peso na decisão de compra, uma estratégia de valorização de marca tornase mais adequada. Há ainda a possibilidade de o consumidor valorizar as conseqüências destes atributos, quando o que ele busca é, primordialmente, os benefícios trazidos pelo consumo.

Alpert (1971) propôs uma tipologia, por meio da qual é possível classificar os atributos que pesam no momento de decisão de compra do consumidor em salientes, importantes ou determinantes. Segundo outras teorias, os atributos também podem ser categorizados em intrínsecos e extrínsecos (Zeithaml, 1988) ou concretos e abstratos (Peter e Olson, 1999).

No entanto, além da identificação e categorização, torna-se importante, da mesma forma, uma tentativa de quantificação da importância relativa destes atributos. Com base nesta necessidade, o presente trabalho visa à analisar a estrutura subjacente à avaliação dos atributos considerados importantes pelos consumidores no momento da compra de condicionadores de ar. Outros objetivos pretendidos com esta pesquisa são: (1) identificar quais são os atributos importantes e determinantes da compra; (2) identificar se, na amostra em que o estudo é conduzido, a importância relativa dos atributos pode ser classificada de acordo com as teorias de atributos encontradas na literatura; e (3) identificar 
a estrutura de avaliação da importância dos atributos sob o ponto de vista dos consumidores.

Na etapa quantitativa, foi aplicada a técnica estatística de análise fatorial sobre os dados de uma amostra composta por compradores e potenciais compradores de aparelhos de ar condicionado. O estudo possui caráter exploratório e aplicado, no qual busca-se entender o comportamento de compra dos clientes. Apresentando uma abordagem que visa à aliar a teoria à prática, no final propõe que a metodologia utilizada possa ser aplicada a outras indústrias, considerando suas idiossincrasias e de forma a identificar a estrutura adequada ao seu mercado e clientes.

Algumas questões de natureza teórica e prática sustentam a escolha das abordagens discutidas para a sustentação deste estudo. É possível classificar os atributos considerados importantes e determinantes pelo consumidor? Será que o consumidor avalia os produtos em apenas duas dimensões? Os atributos intrínsecos e extrínsecos ou concretos e abstratos têm a mesma importância relativa?

\section{Referencial Teórico}

Os consumidores percebem os produtos como pacotes de atributos (Peter e Olson, 1999), nos quais estes são as características, componentes, partes ou aspectos de produtos ou serviços que os consumidores descrevem sobre o produto em questão (Woodruff e Gardial, 1996).

\section{Atributos Salientes, Importantes e Determinantes}

Segundo Alpert (1971), é muito importante identificar as razões pelas quais os consumidores decidem suas compras. Com vistas a propor uma tipologia que auxilie o profissional de marketing a realizar esta tarefa, o autor classifica os atributos como segue abaixo.

. Atributos Salientes: são aqueles atributos que os consumidores conseguem perceber como presentes em determinado produto, marca, empresa ou instituição. Os atributos salientes funcionam como um conjunto total de atributos percebido por determinado público consumidor sem, entretanto, possuir qualquer grau de importância ou determinação no processo de compra do produto. Estes atributos apenas estão reconhecidamente presentes em determinado produto ou marca, para um grupo específico.

Atributos Importantes: são os atributos que determinado grupo de 
consumidores considera importantes no momento da escolha de um produto. Podem ser considerados como subgrupo dos atributos salientes. Não são características determinantes da compra, uma vez que os consumidores, muitas vezes, não os pesam por os considerarem presentes em todos os produtos de determinada categoria da qual se examina a possibilidade de comprar.

. Atributos Determinantes: são aqueles situados entre os atributos importantes que o consumidor examina como capazes de influenciar positivamente a compra. São os atributos cuja existência e percepção apresentam-se para o consumidor como a melhor possibilidade de resposta da satisfação de seus desejos em determinado produto ou marca. São aqueles que permitem discriminar as marcas.

É importante salientar que nem todos os atributos têm a mesma importância aos olhos do consumidor. A importância de um atributo para um indivíduo reflete os valores ou as prioridades que este indivíduo relaciona a cada vantagem oferecida, sempre dependendo das necessidades para as quais ele busca satisfação (Mowen e Minor, 1998).

A importância também depende das percepções dos indivíduos, as quais podem ser seletivas ou relativas. Podem ser seletivas, porque a atenção o é e os indivíduos têm uma tendência a filtrar as informações a que são expostos, sendo que certos elementos são retidos quando respondem às necessidades daquele momento. Atenção seletiva significa que os profissionais de marketing devem despender esforço congruente com a seletividade dos consumidores para atrair a sua atenção. As percepções podem ser relativas, porque as experiências e as expectativas dos indivíduos são diversas, sendo o grau de presença dos atributos percebido, conseqüentemente, de forma diferente.

Assim os indivíduos têm percepções diferentes sobre a presença de determinados atributos, e estas percepções podem estar apoiadas na experiência, nas informações recebidas, no conselho de pessoas conhecidas, na publicidade ou nas impressões puramente pessoais (Blackwell, Miniard e Engel, 2001). Deste modo, de acordo com diversos estudos realizados para medir o grau de influência dos atributos na intenção de compra de bens e serviços, verificou-se que a simples identificação de atributos considerados importantes não permitia conhecer, entre eles, quais determinavam a compra e preferência por determinado produto ou marca. Logo, a identificação de atributos determinantes passou a ser considerada (Alpert, 1971). Para identificá-los, pode-se utilizar diferentes instrumentos de análise estatística, variando conforme a confiabilidade dos dados e a facilidade de obtenção de informações.

Além desta tipologia apresentada, é possível classificar os atributos em outras categorias. As características do produto podem ser divididas em intrínsecas e 
extrínsecas, além de concretas e abstratas. Estas classificações adicionais são descritas a seguir.

\section{Atributos Intrínsecos e Extrínsecos}

Durante o processo de decisão de compra, o consumidor compara as diferentes opções de produtos capazes de satisfazer suas necessidades. Ele seleciona, integra e avalia informações relacionadas às marcas de produtos para chegar a um julgamento. As informações sobre as marcas enquadram-se em duas categorias gerais de atributos: os extrínsecos e os intrínsecos (Zeithaml, 1988). Elementos intrínsecos da oferta incluem os componentes físicos e as características funcionais, tais como design, durabilidade e tamanho. Os atributos extrínsecos, embora se associem ao produto, não fazem parte da sua composição física. Exemplos são o preço e a marca.

Zeithaml (1988) apresentou um trabalho extenso, resumindo a teoria e a pesquisa realizados até então e apontando direções para o estudo das relações entre preço, qualidade e valor. Segundo ela, grande parte dos estudos empíricos tratou o preço como fator extrínseco, sinalizando a qualidade de uma oferta para o cliente. $\mathrm{O}$ preço é, entretanto, apenas um atributo extrínseco entre diversos, sendo que outros podem ser tão ou mais importantes em certos contextos. A autora recomenda redução na ênfase ao preço em favor de estudos que contemplem outros atributos como marca e embalagem. A marca, em particular, é encontrada em outros trabalhos como sendo um elemento extrínseco, que apresenta influência acentuada nas decisões de compra (Aaker, 1991; Keller, 1993). Uma marca, do ponto de vista do consumidor, pode ser definida como um conjunto específico de características, que proporcionam ao consumidor não somente o produto em si, mas também uma série de serviços suplementares, que constituem elementos de diferenciação entre as marcas e que podem influenciar as preferências dos consumidores (Lambin, 2000). De acordo com esta definição, a marca seria, além de um atributo extrínseco, um atributo determinante.

O modelo proposto por Zeithaml (1988) mostra que o processo de decisão de compra é influenciado pelas avaliações dos consumidores quanto aos atributos intrínsecos e extrínsecos de um produto, levando-os a formar percepções de qualidade, preço e valor das diferentes alternativas consideradas para compra. Neste processo, pode-se dizer que os atributos do produto levam o indivíduo a identificar a presença de benefícios ou a ausência de sacrifícios, formando uma percepção geral em relação ao produto.

Embora tenham sido encontrados trabalhos avaliando a influência do ambiente do varejo nas percepções dos consumidores (Akhter, Andrews e Durvasula, 1994; 
Swait e Sweeney, 2000), poucos trabalhos abordaram recentemente a questão dos atributos dos produtos. Uma exceção talvez seja a série de estudos realizados por Baker e colegas (Baker, Levy e Grewal, 1992; Grewal e Baker, 1994; Baker et al., 2002), que utilizaram algumas variáveis do modelo proposto por Zeithaml (1988) para avaliar a percepção dos consumidores. Os trabalhos, no entanto, não tratam diretamente de atributos intrínsecos e extrínsecos.

\section{Atributos Concretos e Abstratos}

Outra classificação possível para os atributos é a categorização entre abstratos e concretos (Peter e Olson, 1999). Sob esta ótica, os atributos são avaliados como partes de um pacote de atributos que os consumidores vêem em um produto. Eles definem o produto por suas características, seus componentes e suas partes e são o que, geralmente, os consumidores utilizarão para descrever um produto, quando solicitados (Woodruff e Gardial, 1996). Entende-se por atributo concreto o que é físico e tangível num produto, como o tamanho do aparelho, no caso de condicionadores de ar; por abstratos, entendem-se as características mais intangíveis, como a qualidade percebida (Peter e Olson, 1999).

Allen (2001) considera atributos tangíveis ou objetivos aqueles perceptíveis por meio dos cinco sentidos humanos, enquanto que intangíveis são as imagens do produto tais como beleza, estética ou prestígio. Segundo o autor os atributos tangíveis e intangíveis são julgados de maneiras diferentes pelos consumidores e, portanto, devem ser analisados distintamente.

Os atributos são, ainda, o que produz conseqüências no produto real (ValetteFlorence e Rapacchi, 1991). As conseqüências representam comportamentos em situações específicas e são resultantes das considerações mais subjetivas de um consumidor acerca do uso de um produto e os resultados percebidos, sejam eles positivos ou negativos, desejados ou não (Woodruff e Gardial, 1996). Em relação às conseqüências, Peter e Olson (1999) as dividem em funcionais, advindas de resultados tangíveis da experiência direta de consumo de um produto, como o saciamento da fome ao se comer um sanduíche; e psicológicas, provenientes de resultados psicológicos ou sociais do consumo de um produto, tais como imaginar a opinião dos amigos a respeito da roupa que se está vestindo. As conseqüências, quando positivas, são os benefícios que a compra ou o consumo de determinado produto acarretam.

Woodruff e Gardial (1996) sugerem que os atributos fazem parte de uma hierarquia de valor, que conecta as características do produto às características psicológicas do consumidor. De acordo com esta perspectiva, os atributos concretos/tangíveis 
são os primeiros percebidos dos consumidores, seguidos dos atributos abstratos e das conseqüências funcionais e psicológicas (vide Figura 1).

\section{Figura 1: Hierarquia de Valor}

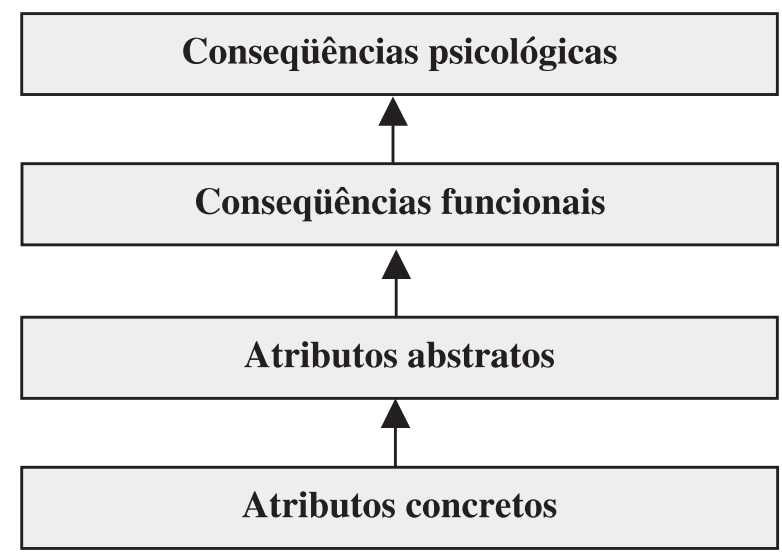

Fonte: adaptado de Woodruff e Gardial (1996).

Considerando-se estas classificações, foi realizada uma pesquisa para explorar como os consumidores avaliam os atributos relacionados a condicionadores de ar, conforme se descreve a seguir.

\section{Método}

Segundo Churchill (1999), a pesquisa exploratória é um meio de gerar idéias, aumentar a familiaridade do pesquisador com o tema em investigação e esclarecer conceitos. Portanto, para se atingir os objetivos propostos para este trabalho, foi desenvolvido um estudo de caráter exploratório, dividido em uma fase qualitativa e outra quantitativa.

\section{Etapa Qualitativa}

Na primeira etapa, procurou-se identificar quais eram os atributos considerados mais importantes pelos consumidores no momento da compra de condicionadores de ar de janela. Com o objetivo de gerar uma lista de atributos, foi realizada uma série de entrevistas em profundidade, realizadas pessoalmente pelas autoras com o auxílio de roteiro especialmente preparado para este fim, o qual continha questões abertas e permitia que o entrevistado trouxesse à tona o que ele acha relevante, 
ao invés de conduzir a entrevista pela noção de relevância das pesquisadoras (Lincoln e Guba, 1985).

Nessas entrevistas, foram consideradas todas as marcas de condicionadores de ar disponíveis no mercado, e durante uma hora, em média, o processo de compra e uso do produto ar condicionado foi discutido com cada um de 12 consumidores finais, selecionados por conveniência pelo critério de ter comprado um aparelho condicionador de ar nos seis meses anteriores à entrevista. As entrevistas cessaram quando as informações fornecidas pelos entrevistados começaram a se repetir e não mais se acrescentavam novos elementos e atributos com novas entrevistas (Malhotra, 2001). Uma análise de conteúdo simples gerou a listagem dos atributos citados pelos consumidores e a sua ordem de acordo com o número de citações (foi feita uma contagem de palavras). A partir disso, elaborou-se o instrumento de coleta de dados utilizado na fase quantitativa da pesquisa.

De acordo com os resultados da fase qualitativa, foram identificados 26 itens considerados no momento da compra, os quais fizeram parte do questionário. Os itens tiveram a sua importância relativa mensurada com uma escala do tipo Likert, variando de 1 (pouca importância) a 5 (muita importância). Foi realizado préteste do questionário com 10 consumidores finais, o que gerou algumas modificações quanto à redação, formulação das questões e seqüência das perguntas, de forma a facilitar o preenchimento do instrumento. Adicionalmente, foram acrescentadas questões sobre o perfil da amostra.

\section{Etapa Quantitativa}

Esta etapa caracterizou-se pela aplicação do questionário desenvolvido na etapa anterior com uma amostra selecionada por conveniência. Para a análise dos dados, foram empregadas ferramentas estatísticas com o auxílio do software SPSS (Statistical Package for the Social Sciences).

\section{Coleta de Dados e Amostra}

A amostra da segunda etapa, selecionada por conveniência, foi composta por clientes potenciais que buscaram informações sobre condicionadores de ar nos pontos de venda da cidade de Porto Alegre, RS. A técnica de coleta de dados foi entrevista face a face nos pontos de venda, realizada por duas entrevistadoras que receberam treinamento para este fim. As entrevistadoras, eram promotoras de vendas de uma indústria de condicionadores de ar e, como tal, cumpriam um roteiro semanal de visita a lojas do varejo para distribuir material de exposição, 
treinar os vendedores e fornecer informações aos clientes. Para a realização da pesquisa, a promotora/entrevistadora aplicava o questionário naqueles clientes que a abordavam e concordavam em responder às questões. Considerou-se estas pessoas adequadas para responder ao questionário, porquanto o fato de estarem buscando informações sobre o aparelho demonstra interesse na compra e capacidade para responder sobre o que é importante nesse processo de decisão.

Tendo em vista que a amostra foi selecionada por conveniência, ela não é representativa da população da cidade e tampouco dos clientes potenciais de condicionadores de ar; portanto um número de casos mínimo para permitir a condução das análises estatísticas foi definido como desejável. Visto que seria aplicada análise fatorial para analisar a dimensionalidade dos atributos, a amostra mínima deveria ser de 130 casos, pois é indicado que se tenha cinco casos para cada variável da escala (Hair Jr. et al., 1998). Em estudos exploratórios, como neste caso, a representatividade da amostra passa a ser preocupação secundária, já que o principal objetivo é analisar um fenômeno e não extrapolar os resultados para a população (Churchill, 1999).

Conforme mostra a Tabela 1, a amostra final foi constituída de 187 pessoas, sendo $50,8 \%$ do sexo masculino e $49,2 \%$ do sexo feminino. A faixa de idade predominante foi dos 25 aos 44 anos, com $64,2 \%$ dos respondentes inseridos nesta categoria.

\section{Tabela 1: Caracterização da Amostra}

\begin{tabular}{l|ccc}
\hline & Características & Freqüência & Percentual \\
\hline Sexo & Masculino & 95 & 50,8 \\
& Feminino & 92 & 49,2 \\
\hline Idade & De 15 a 24 anos & 33 & 17,6 \\
& De 25 a 34 anos & 60 & 32,1 \\
& De 35 a 44 anos & 60 & 32,1 \\
& De 45 a 54 anos & 24 & 12,8 \\
& Acima de 55 anos & 10 & 5,3 \\
\hline Total & & 187 & 100.00 \\
\hline
\end{tabular}

Ao responderem a pergunta 'qual a importância que você dá a um aparelho de ar condicionado em um ambiente?', 47,6\% dos entrevistados considerou muito importante e 43,9\% considerou importante, somando 91,5\% das respostas entre estes dois itens. Esta informação revela que os consumidores classificam o aparelho de ar condicionado como um dos principais componentes de um ambiente confortável e agradável. Apenas 3,2\% considerou a presença do aparelho pouco importante e não houve nenhuma citação para 'sem importância'. Quase 20\% 
dos entrevistados indicou que pretende comprar um aparelho nos próximos seis meses. A Tabela 2 explicita esses resultados.

Tabela 2: Importância do Aparelho de Ar Condicionado

\begin{tabular}{l|lcc}
\hline & & Freqüência & Percentual \\
\hline Importância & Muito Importante & 89 & 47,6 \\
& Importante & 82 & 43,9 \\
& Indiferente & 10 & 5,3 \\
& Pouco Importante & 6 & 3,2 \\
& Total & 187 & 100,0 \\
\hline Pretende comprar & Sim & 37 & 19,8 \\
& Não & 150 & 80,2 \\
\hline Total & & 187 & 100,0 \\
\hline
\end{tabular}

Para se atingir o principal objetivo deste trabalho, foi aplicada Análise Fatorial Exploratória (AFE), bem como foi calculado o Alpha de Cronbach para verificar a confiabilidade da escala. A análise dos dados e os resultados são apresentados a seguir.

\section{Análise dos Dados e Resultados}

\section{Análise Fatorial Exploratória}

Considerando-se que os atributos identificados na fase qualitativa formaram uma escala de 26 itens, tornou-se relevante verificar como os dados desses atributos se distribuíam, a fim de distinguir as dimensões pelas quais eles são avaliados pelos respondentes. Para atingir este objetivo, foi utilizado o procedimento estatístico de Análise Fatorial Exploratória, com a extração de componentes principais sobre a matriz de correlações, que se mostrou adequada aos propósitos desse trabalho.

A análise fatorial é um procedimento estatístico mutivariado, cuja finalidade básica é agrupar variáveis altamente correlacionadas. Uma vantagem deste método é que ele permite analisar, ao invés de, por exemplo, 26 variáveis, um conjunto menor de fatores que são compostos por estas variáveis e, portanto, trazem consigo suas características estatísticas (Lehmann, Gupta e Steckel, 1998). Além disso, a análise fatorial assume que as 26 variáveis são manifestações de um número menor - digamos, quatro - de constructos, variáveis latentes ou simplesmente fatores. Esses constructos são as dimensões de avaliação do produto 
e são encontrados por meio da correlação das variáveis (Hair Jr. et al., 1998). Os principais resultados da AFE são: (1) o percentual de variância explicada por toda a solução fatorial e por cada fator; e (2) as cargas fatoriais de cada variável no respectivo fator, que representam a correlação daquela variável com o fator (Hair Jr. et al., 1998).

A AFE foi efetuada com rotação ortogonal VARIMAX ${ }^{(1)}$, que simplifica a interpretação dos fatores que não estejam claros. Em particular, é comum que algumas variáveis estejam relacionadas ao primeiro fator apenas moderadamente ou mesmo que estejam relacionadas a mais de um fator. A rotação ajusta as cargas fatoriais aos componentes, de forma que se torne mais claro em qual fator determinada variável tem carga mais elevada (Lehmann, Gupta e Steckel, 1998).

O critério de corte para a retenção dos fatores foi o autovalor maior ou igual a 1. Este critério supõe que uma variável sozinha possui um autovalor de 1 e que um eixo (fator) deve ser capaz de explicar mais variância do que uma variável isolada, em média. Assim são retidos todos os eixos para os quais o autovalor é igual ou superior a 1 (Hair Jr. et al., 1998).

A aplicação deste critério de corte na análise fatorial com os dados da pesquisa sugeriu uma estrutura composta por sete fatores. Cada dimensão é constituída de uma combinação linear de variáveis, as quais são relativamente pesadas dentro de cada dimensão por meio dos autovalores padronizados. Ou seja, cada uma destas 7 dimensões é composta pelas variáveis que têm maior autovalor e representam a maior parte da variância daquela dimensão.

Esta solução, entretanto, gerou matrizes de cargas fatoriais com uma estrutura de difícil interpretação. Alguns itens apresentavam elevadas cargas em mais de um fator, o que poderia sugerir sua supressão, e dois fatores explicavam relativamente pouca variância (6,2\% e 7\%). Estes resultados indicavam possível redução do número de dimensões da solução fatorial.

Na tentativa de encontrar melhor solução, adotou-se um procedimento ligeiramente modificado para a extração dos fatores. A análise fatorial foi novamente produzida sobre a matriz de correlações com rotação VARIMAX; mas, desta vez, as dimensões foram previamente fixadas em 6 (restituindo 72,043\% da variância) e, subseqüentemente, em 5 (restituindo 68,27\% da variância). Novamente, as soluções eram de difícil interpretação e apresentavam instabilidade entre os fatores quando itens com baixas cargas fatoriais (abaixo de 0,5) eram suprimidos da análise. Repetiu-se o processo, sugerindo-se a manutenção de 4 fatores. Com esse procedimento, o padrão de cargas fatoriais resultante mostrouse razoavelmente similar entre os fatores, e a comparação entre as dimensões geradas tornou-se mais fácil e consistente. 
A estrutura constituída de 4 componentes revelados pela análise fatorial explica 58,7\% da variância. Deste total de variância explicada, o primeiro componente contribui com $19,66 \%$, o segundo explica $15,05 \%$, o terceiro $14,38 \%$ e o quarto $9,61 \%$.

\section{Confiabilidade da Escala}

Para avaliar a confiabilidade da escala utilizada, foi adotado o método de consistência interna, que avalia a homogeneidade do conjunto de itens. Para isso, utilizou-se o cálculo do coeficiente Alpha de Cronbach, que se constitui em um dos procedimentos mais adotados para avaliar a confiabilidade de uma escala (Malhotra, 2001). O coeficiente Alpha de Cronbach foi calculado separadamente para as quatro dimensões encontradas.

O cálculo para todos os itens da escala apresentou valor igual a 0,846 . As dimensões apresentaram os seguintes resultados: D1 $=0,8555$; D2 $=0,7833$; D3 $=0,8207$; D4=0,5527. Os valores encontrados para as dimensões 1 , 2 e 3 sugerem que a escala para cada uma destas dimensões apresenta boa confiabilidade. A dimensão 4 está abaixo do índice de 0,6 indicado por Malhotra (2001), o que significa que esta medida apresenta confiabilidade insatisfatória da consistência interna. Baixa confiabilidade indica que a escala não produz resultados consistentes na extensão em que as medidas são tomadas repetidamente.

\section{Purificação da Escala}

Com base na estrutura fatorial composta por 4 fatores, foi feita uma purificação da escala com a retenção das variáveis que explicavam a maior parte da variância. De acordo com o critério adotado, indicado por Hair Jr. et al. (1998), variáveis com cargas fatoriais acima de 0,5 são consideradas significantes, o que indica alta correlação da variável com o fator. Desta forma, foram suprimidas 7 variáveis da escala original de 26 itens, resultando em 19 itens. Os itens suprimidos foram tecnologia, durabilidade, existência de controle remoto, facilidade de manutenção, vendedor conhecer características, fabricante oferecer instalação e site do fabricante.

Este procedimento conduziu à realização de outra análise fatorial, nova análise da estrutura fatorial decorrente e novo cálculo dos coeficientes de confiabilidade. Após este procedimento, obteve-se uma solução que parece ser a mais adequada, já que apresenta estrutura relativamente estável em relação à solução anterior e permite boa interpretação. Esta estabilidade observada é caracterizada por um número menor de inconsistências entre as variáveis e a dimensão. As características da escala purificada são apresentadas na Tabela 3. 
Tabela 3: Coeficientes de Confiabilidade para as Dimensões da Escala Purificada

\begin{tabular}{c|cc}
\hline & $\mathbf{N}^{\circ}$ de itens & Coeficiente Alpha \\
\hline Geral & 19 & 0,7842 \\
D1 & 6 & 0,7969 \\
D2 & 4 & 0,7833 \\
D3 & 5 & 0,7189 \\
D4 & 4 & 0,5527 \\
\hline
\end{tabular}

Os fatores 1, 2 e 3 apresentam bons índices de confiabilidade. A dimensão 4 está, novamente, um pouco abaixo do índice de 0,6 indicado por Malhotra (2001), o que significa que a medida não apresenta boa confiabilidade.

\section{Dimensionalidade do Modelo Fatorial}

As análises fatoriais efetuadas permitiram identificar a existência de quatro dimensões de atributos considerados importantes na compra de condicionadores de ar. Estes quatro fatores explicam 65,23\% da variância, o que reforça o resultado de que a solução obtida é adequada para descrever o conjunto de variáveis.

A dimensão que mais contribui para a variância explicada de 65,23\% do modelo fatorial obtido é a dimensão 1 (18,87\%), a qual se refere a atributos extrínsecos e abstratos relacionados a preço e distribuição. A dimensão 2 representa os atributos do produto que são considerados na avaliação dos consumidores e explicam a segunda maior parcela da variância $(18,10 \%)$. Neste fator são encontrados atributos intrínsecos, extrínsecos, abstratos e concretos, fato que será abordado novamente na interpretação dos resultados. A dimensão 3, que contribui com 16,02\% da variância explicada, reflete os atributos extrínsecos e abstratos relacionados, principalmente, à facilidade e conveniência na compra do produto. Uma vez que a pesquisa considerou os atributos importantes para a compra do produto, este resultado vem a ser coerente. E, por fim, a dimensão 4, contribuindo com $12,23 \%$ da variância explicada, reúne os atributos intrínsecos do produto, tanto concretos quanto abstratos, que são características relacionadas ao uso do aparelho. A Tabela 4 apresenta a dimensionalidade dos atributos e as cargas fatoriais de cada variável em seu respectivo fator.

A interpretação das quatro dimensões identificadas permite que elas sejam denominadas de acordo com o que as variáveis componentes do fator estão propondo mensurar. Uma síntese das características das quatro dimensões identificadas é apresentada no Quadro 1. 


\section{Tabela 4: Cargas Fatoriais para as Dimensões de Atributos}

\begin{tabular}{l|cccc}
\hline Variáveis & D1 & D2 & D3 & D4 \\
\hline Preço & 0,643 & & & \\
Condições de pagamento & 0,857 & & & \\
Pronta-entrega & 0,782 & & & \\
Prazo de entrega & 0,769 & & & \\
\hline Marca & & 0,791 & & \\
Marca gaúcha & & 0,644 & & \\
Consumo & & 0,821 & & \\
Facilidade de uso & & 0,511 & & \\
Aparelho ser portátil & & 0,633 & & \\
Tamanho do aparelho & & 0,844 & & 0,785 \\
\hline Ter rede de assistência & & & 0,767 & \\
Exposição na loja & & & 0,701 & 0,765 \\
Facilidade de encontrar & & & 0,558 & \\
Variedade de modelos na loja & & & & 0,560 \\
Propaganda & & & & 0,705 \\
\hline Nível de ruído & & & & \\
Estética & & & & \\
Potência & & & & \\
Qualidade & & & & \\
\hline \% Variância Explicada & $\mathbf{1 8 , 8 7 4}$ & $\mathbf{1 8 2 1 0 8}$ & \\
\hline
\end{tabular}

\section{Quadro 1: Características das Dimensões de Atributos do Produto}

\begin{tabular}{|c|l|l|}
\hline Dimensão & \multicolumn{1}{|c|}{ Variáveis } & \multicolumn{1}{|c|}{ Características } \\
\hline $\begin{array}{c}\text { Preço e } \\
\text { Distribuição }\end{array}$ & $\begin{array}{l}\text { Preço, condições de pagamento, } \\
\text { pronta-entrega, prazo de entrega. }\end{array}$ & $\begin{array}{l}\text { Esta dimensão é formada por atributos } \\
\text { extrínsecos e abstratos relacionados a preço e } \\
\text { distribuição. São os atributos determinantes, } \\
\text { pois fazem parte da dimensão de maior peso } \\
\text { para os consumidores. }\end{array}$ \\
\hline $\begin{array}{c}\text { Marca e } \\
\text { Conveniência do } \\
\text { Uso do Produto }\end{array}$ & $\begin{array}{l}\text { Marca, marca gaúcha, consumo, } \\
\text { facilidade de uso, aparelho ser } \\
\text { portátil, tamanho do aparelho. }\end{array}$ & $\begin{array}{l}\text { Caracteriza dimensão de avaliação de } \\
\text { características do produto É possível } \\
\text { identificar atributos extrínsecos e abstratos } \\
\text { (marca, marca gaúcha), intrínsecos e concretos } \\
\text { (consumo, aparelho ser portátil, tamanho do } \\
\text { aparelho) e intrínseco e abstrato (facilidade de } \\
\text { uso). }\end{array}$ \\
\hline $\begin{array}{c}\text { Facilidade e } \\
\text { Conveniência na } \\
\text { Compra }\end{array}$ & $\begin{array}{l}\text { Ter rede de assistência, exposição } \\
\text { na loja, facilidade de encontrar, } \\
\text { variedade de modelos na loja, } \\
\text { propaganda. }\end{array}$ & $\begin{array}{l}\text { Consiste em outra dimensão de atributos } \\
\text { extrínsecos e abstratos. Estes serviços estão } \\
\text { relacionados à facilidade e conveniência na } \\
\text { compra e uso subseqüente do produto. }\end{array}$ \\
\hline $\begin{array}{c}\text { Características } \\
\text { Indicadoras de } \\
\text { Qualidade }\end{array}$ & $\begin{array}{l}\text { Nível de ruído, estética, potência, } \\
\text { qualidade. }\end{array}$ & $\begin{array}{l}\text { Dimensão de atributos intrínsecos do produto. } \\
\text { São as características do produto relacionadas } \\
\text { ao uso do produto e são concretos (nível de } \\
\text { ruído, potência) e abstratos (estética, } \\
\text { qualidade). }\end{array}$ \\
\hline
\end{tabular}


Cada dimensão foi interpretada com base nas teorias de atributos apresentadas anteriormente (Alpert, 1971; Zeithaml, 1988; Peter e Olson, 1999), de maneira que as dimensões pudessem ser nomeadas de acordo com o que elas representam. A análise dos tipos de atributos constituintes de cada fator permitiu que a dimensão 1 fosse identificada como representando os atributos referentes à preço e distribuição; a dimensão 2 com atributos referentes à marca e conveniência no uso do produto; a dimensão 3 relacionada com a facilidade e conveniência na compra; e a dimensão 4 como atributos descritores de características indicadoras de qualidade.

Na dimensão preço e distribuição, considerando-se que estas variáveis fazem parte do fator que explica a maior parte da variância do modelo fatorial que teve por base a mensuração da importância relativa de cada atributo, sugere-se que estes itens são os atributos mais importantes ou determinantes da compra. Estas são as características que devem receber atenção especial.

A dimensão marca e conveniência do uso do produto mistura atributos extrínsecos e intrínsecos. Entretanto, nota-se que os atributos extrínsecos são referentes à marca (marca, marca gaúcha) e, portanto, podem também ser caracterizados como abstratos. Os atributos intrínsecos desta dimensão, por sua vez, dividem-se em concretos (consumo, aparelho ser portátil, tamanho do aparelho) e abstratos (facilidade de uso). Apesar disso, ambos descrevem características relacionadas à utilização do aparelho.

Na dimensão facilidade e conveniência na compra foram inseridos apenas atributos extrínsecos e abstratos, os quais se referem, especificamente, à compra do produto. É interessante observar como os consumidores consideram importante as variáveis desta dimensão, pois indicam que a facilidade na compra, no sentido de minimizar o esforço do cliente, é avaliada de forma positiva. Cabe lembrar que todas as variáveis da pesquisa foram indicadas espontaneamente pelos entrevistados na etapa qualitativa.

A última dimensão refere-se à características indicadoras de qualidade e considera atributos intrínsecos do produto. Estes, por seu turno, são divididos em concretos (nível de ruído, potência) e abstratos (estética, qualidade). São, basicamente, as características do produto relacionadas ao uso do produto.

Todas as dimensões avaliaram atributos considerados importantes, em algum grau, pelos consumidores. No entanto, conforme explicado anteriormente, sugerese especial atenção aos itens da dimensão 1, que explica a maior parte da variância e pode conter os atributos determinantes para os consumidores. 


\section{Discussão}

Percebe-se que os resultados indicaram atributos abstratos como componentes do primeiro fator. Tendo em vista que as conseqüências funcionais e psicológicas resultam da percepção dos atributos (Peter e Olson, 1999), este resultado não é contraditório à hierarquia apresentada na Figura 1, já que os atributos abstratos/ intangíveis estariam em nível mais elevado da hierarquia e mais próximos das características psicológicas dos consumidores, sendo, conseqüentemente, considerados mais importantes sob o ponto de vista deles. Esse resultado pode demonstrar que na compra do tipo de produto em questão, o consumidor considera com mais veemência os serviços oferecidos pela empresa.

Alpert (1971) propôs uma tipologia abrangente, baseada na importância considerada pelo consumidor em relação aos atributos. Zeithaml (1988) e Peter e Olson (1999) definem os atributos com base em características funcionais, físicas ou não, facilitando a identificação das suas peculiaridades e, conseqüentemente, a forma de ação mercadológica a ser realizada sobre eles. Dessa forma, os resultados deste trabalho têm implicações para os gerentes de marketing e para a pesquisa.

Nota-se que a preocupação principal dos consumidores reside nas qualidades extrínsecas e abstratas dos produtos. Pode-se considerar que os consumidores atribuem mais peso às características simbólicas e de imagem do produto, que conferem atributos mais intangíveis e são conseqüência de uma avaliação holística, intuitiva e mais afetiva do produto (Allen, 2002). Em segundo lugar, surgiram os atributos intrínsecos e concretos. Eles são formados quando os consumidores, enquanto avaliando e escolhendo o produto, pesam as suas características utilitárias e tangíveis de maneira sistemática, atributo por atributo (Allen, 2002).

\section{Considerações Finais}

Entende-se que o trabalho alcançou os objetivos propostos, na medida em que mostrou as dimensões de avaliação dos atributos considerados importantes pelos clientes, traçando um paralelo com a teoria. Conseqüentemente, o estudo gerou algumas implicações gerenciais e acadêmicas.

\section{Implicações Gerenciais}

O trabalho traz implicações gerenciais interessantes para a administração de 
marketing, uma vez que mostra os atributos importantes sob o ponto de vista do cliente. Com estas informações, as empresas podem desenvolver ações pontuais para melhorar a oferta destes itens indicados pelos consumidores. O processo de compra dos indivíduos torna-se compreensível quando são identificados os atributos relevantes neste processo, que são aqueles que indicam benefícios importantes ou que reduzem os sacrifícios e/ou o esforço do comprador. É nesta capacidade de os atributos indicarem para o comprador a presença de benefícios ou a ausência de sacrifícios que reside a sua relevância para o administrador de marketing.

No caso desta pesquisa, os atributos considerados mais importantes foram aqueles extrínsecos e abstratos e, portanto, a comunicação do produto deve centrarse nessas características. Assim, os resultados fornecem uma orientação para a identificação de quais atributos salientar em propaganda e na imagem da marca. Considerando-se que os atributos mais importantes foram aqueles relacionados à preço e distribuição, sugere-se que sejam oferecidos aos clientes e comunicados, de forma que eles percebam que há um diferencial na oferta da empresa em relação a estes serviços.

É interessante para as empresas do setor, analisar o posicionamento das marcas concorrentes de acordo com a visão dos clientes (o que pode ser feito por meio de mapas perceptuais), de maneira que possam se posicionar melhor no mercado e sejam mais bem vistas pelos consumidores. A abordagem aqui adotada indica quais características devem ser favorecidas na formação da estratégia de posicionamento, de modo que esta seja coerente com o que o consumidor realmente considera no momento da compra do produto.

\section{Implicações Acadêmicas}

Em termos acadêmicos, o trabalho mostra uma forma de identificar as dimensões psicográficas com as quais os consumidores avaliam um produto - neste caso, especificamente, aparelhos de ar condicionado - sob aspectos intrínsecos, extrínsecos, concretos e abstratos. A etapa qualitativa revelou que atributos extrínsecos são avaliados como produto ampliado, como parte das características de um produto. Os resultados da análise fatorial sugerem que, com exceção da dimensão marcas e conveniência no uso do produto, os consumidores percebem os atributos extrínsecos em uma dimensão diferenciada dos atributos intrínsecos.

A metodologia utilizada neste trabalho pode (e deve) ser reaplicada em outros contextos e com outros produtos, de modo a identificar os atributos considerados importantes pelos consumidores naquele caso específico. Esta reaplicação é importante tanto em termos acadêmicos, visando a verificar se as dimensões se comportam da mesma maneira em situações diferentes da analisada, quanto em 
termos gerenciais. Esta última torna-se mais crítica, na medida em que é desejável por parte da empresa maior aplicabilidade do estudo, pois, mediante estudos adicionais, será possível identificar com maior precisão os atributos importantes para a indústria em questão e, da mesma forma, verificar como os consumidores avaliam estes atributos.

Em pesquisas futuras sugere-se que seja dispensada atenção ao aperfeiçoamento do método utilizado, como, por exemplo, cuidados com a representatividade da amostra. A dimensão características indicadoras de qualidade apresentou um coeficiente de confiabilidade abaixo do indicado pela literatura (Malhotra, 2001), sugerindo que a escala pode estar inadequada, ao menos no modo como foi constituída para este caso.

Outra sugestão em termos metodológicos é a aplicação da técnica laddering, que consiste em um método qualitativo de entrevista, no qual o entrevistador questiona os participantes sobre quais atributos eles utilizam para discriminar marcas e porque esses atributos são importantes, elaborando repetidamente sobre as respostas para gerar informações mais ricas. A técnica é particularmente interessante por revelar relações entre os valores pessoais humanos, a importância dos atributos do produto e o comportamento de compra.

Outras questões que não eram alvo de respostas deste estudo, podem ser levantadas e verificadas em estudos posteriores. Por exemplo, qual é a importância relativa dos atributos intrínsecos, extrínsecos, concretos e abstratos quando o consumidor julga ou avalia uma marca em determinada categoria de produtos? Como o consumidor percebe a diferenciação de produtos e/ou marcas, considerando-se os tipos de atributos? A importância dos atributos é afetada pelo nível de envolvimento dos consumidores com a categoria de produtos?

Pode-se também considerar as conseqüências do produto para o indivíduo e a influência dos valores pessoais no processo de decisão de compra. Um exemplo de trabalho recente nesta área consiste na série de estudos realizados por Allen e colegas (Allen, 2001; Allen, Ng e Wilson, 2002), que propõem relações diretas e indiretas (com a mediação da importância dos atributos do produto) entre valores pessoais e comportamento de compra. Segundo os autores, os modelos tradicionais consideram que os valores humanos apenas influenciam as escolhas dos consumidores por meio dos atributos do produto; isto é, os consumidores avaliam os atributos e a partir de um cálculo mental de utilidade determinam as suas escolhas. Por exemplo, se um consumidor deposita maior importância no valor pessoal de segurança, ele deve comprar apenas produtos que sejam considerados seguros por ele. Se este indivíduo está decidindo sobre a compra de um carro, ele pode comparar diferentes carros de acordo com os seus atributos relacionados à segurança e escolher aquele com a maior função utilidade. 
O modelo proposto por Allen e colegas, entretanto, revela que o modelo tradicional assume que o consumidor é estritamente racional, sem considerar julgamentos holísticos, intuitivos ou afetivos. Segundo os autores, a perspectiva proposta por eles foi pouco abordada em comportamento do consumidor e pode ser analisada à luz da teoria de valores pessoais. É sugerido, por exemplo, que os valores moldam as escolhas dos consumidores quando a avaliação do produto é sistemática ou funcional, influenciando a importância dos aspectos tangíveis do produto, e também quando está sendo feita uma avaliação simbólica, holística ou afetiva. Dada a existência dessas questões que merecem investigação, mostrase necessária a continuidade de estudos na área no contexto brasileiro.

\section{Nota}

${ }^{1}$ O procedimento de rotação dos fatores VARIMAX foi escolhido por buscar fatores distintos e não correlacionados entre si e por ser o procedimento padrão de rotação. Após sugestão de um dos revisores, foi analisada a possibilidade de utilizar rotação OBLIMIN, que permite correlação entre os fatores. Entretanto, esta solução não apresentou melhorias em relação à solução com rotação VARIMAX.

\section{ReferênCIAS Bibliográficas}

\section{AAKER, D.}

Managing brand equity. New York: Free Press, 1991.

AKHTER, S. H.;

ANDREWS, J. C.;

DURVASULA, $S$.

The influence of retail store environment on brand-related judgments. Journal of Retailing and Consumer Services, v. 1, n. 2, p. 67-76, 1994.

\section{ALLEN, M.}

A practical method for uncovering the direct and indirect relationships between human values and consumer purchases. Journal of Consumer Marketing, v. 18, n. 2, p. 102-117, 2001.

ALLEN, M. W.;

NG, S. H.;

WILSON, M.

A functional approach to instrumental and terminal values and the value-attitude-behavior system of consumer choice. European Journal of Marketing, v. 36, n.1/2, p. 111138, 2002. 
ALPERT, M.

Identification of determinant attributes: a comparison of methods. Journal of Marketing Research, v. 8, n. 2, p. 184-191, May 1971.

BAKER, J. et al.

The influence of multiple store environment cues on perceived merchandise value and patronage intentions. Journal of Marketing, v. 66, n. 2, p. 120-141, Apr. 2002.

BAKER, J.;

LEVY, M.;

GREWAL, D.

An experimental approach to making retail store environmental decisions. Journal of Retailing, v. 68 , n. 4, p. 445-463, Winter 1992.

BLACKWELL, R. D.;

MINIARD, P. W.;

ENGEL, J. F.

Consumer behavior. 9. ed. Orlando: Harcourt, 2001.

CHURCHILL JR., G. A. Marketing research: methodological foundations. 8. ed. Orlando: Dryden Press, 1999.

GREWAL, D.;

BAKER, J.

Do retail store environmental factors affect consumers' price acceptability? An empirical examination. International
Journal of Research in

Marketing, v. 11, n. 2, p. 107-115, Fall 1994.

HAIR JR., J. F. et al.

Multivariate data analysis. 5. ed. New Jersey: Prentice Hall, 1998.

KELLER, K. L.

Conceptualizing, measuring, and managing customer-based brand equity. Journal of Marketing, v. 57, n. 1, p. 1-22, Jan. 1993.

LAMBIN, J.-J.

Marketing estratégico. 4. ed. São Paulo: Ernesto Reichmann, 2000.

LEHMANN, D.;

GUPTA, S.;

STECKEL, J. H.

Marketing research. Reading, MA: Addison-Wesley, 1998.

LINCOLN, Y. S.;

GUBA, E. G.

Naturalistic inquiry. London:

Sage Publications, 1985.

MALHOTRA, N.

Pesquisa de marketing: uma orientação aplicada. Porto Alegre: Bookman, 2001.

MOWEN, J. C.;

MINOR, M.

Consumer behavior. 5. ed. New York: Prentice-Hall, 1998. 
PETER, J. P.;

OLSON, J. C.

Consumer behavior and marketing strategy. 5. ed. Boston: Irwin/ McGraw-Hill, 1999.

SWAIT, J.;

SWEENEY, J.

Perceived value and its impact on choice behavior in a retail setting. Journal of Retailing and Consumer Services, v. 7, p. 7788, 2000.

VALETTE-FLORENCE, P.;

RAPACCHI, B.

Improvements in means-end chains analysis: using graph theory and correspondence analysis. Journal of Advertising Research, v. 31, n. 1, p. 30-46, Feb./Mar. 1991.

WOODRUFF, R. B.;

GARDIAL, S. F.

Know your customer: new approaches to understanding customer value and satisfaction. Malden: Blackwell Business, 1996.

ZEITHAML, V. A.

Consumer perceptions of price, quality, and value: a means-end model and synthesis of evidence. Journal of Marketing, v. 52, n. 2, p. 2-22, July 1988. 